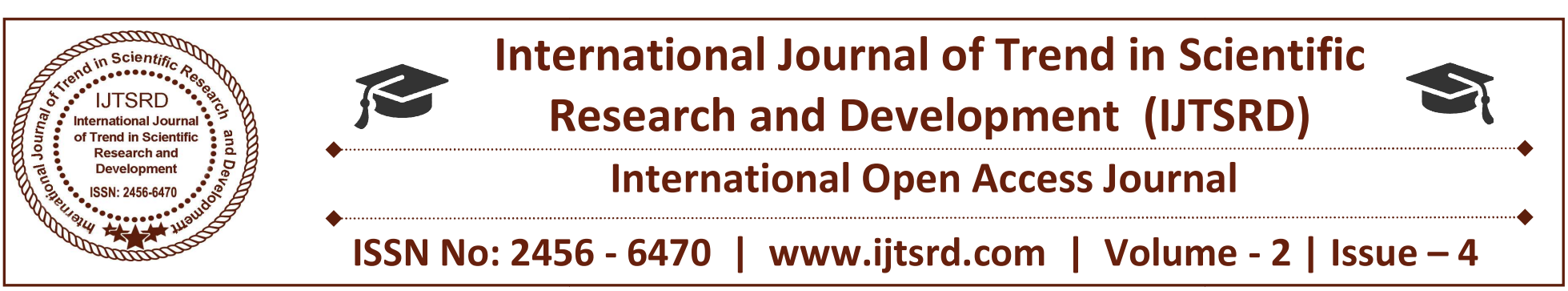

\title{
Effect of Different Carbon Sources on in Vitro Shoot Regeneration of Petunia Hybrid Hort. (Vilm)
}

\author{
Assia Zahoor ${ }^{1}$, Jasfeeda Qadir ${ }^{2}$, Dr. Seema Singh ${ }^{3}$ \\ ${ }^{1}$ Student, ${ }^{2} \mathrm{Ph}$.D Research Scholar, ${ }^{3} \mathrm{Sr}$. Assistant Professor \\ ${ }^{1,2,3}$ Plant Tissue Culture Research Laboratory, Department of Botany, \\ University of Kashmir, Hazratbal, Srinagar, India
}

\begin{abstract}
:
The present study was undertaken in order to develop an efficient in vitro propagation protocol for Petunia hybrid using leaf as an explant. The effects of different concentrations of five different carbon sources i.e., sucrose, glucose, mannose, arabinose and maltose was investigated on shoot regeneration of Petunia hybrid. Shoot regeneration occurred on MS medium supplemented with sucrose, glucose and maltose. No growth was obtained on MS medium when mannose and arabinose were used as carbon source. Best shoot regeneration with maximum shoot length and maximum number of shoots was obtained on MS medium supplemented with 3\% carbon within 11 days with $70 \%$ culture response. Shoot regeneration was also obtained on MS medium supplemented with glucose and maltose within 18 and 24 days with 50 and $30 \%$ culture response respectively.
\end{abstract}

Keywords: Explant, Maltose, MS medium, Petunia hybrid, Regeneration

\section{INTRODUCTION}

Petunia is the herbaceous ornamental plant belonging to the family Solanaceae and consists of 35 species. The geographical distribution includes temperate and sub tropical regions of Argentina, Uruguay, Paraguay, Bolivia and Brazil (Ando et al., 2005). The basic Petunia flower is funnel shaped. Leaves and stems are sticky to the touch and have a distinctive odor. It has high economic importance in global horticulture and is grown for decorative purposes in gardens and landscape design projects, as house plants, for cut flowers and specimen display. Petunias are a great flowering bedding plant to add to landscape prior to the end of winter/beginning of spring. Petunia hybrida is a petunia plant "nothospecies" (hybrid), which encompasses all hybrid species of petunia between P.axillarisand P.integrifolia. Petunia hybrid plants were originally produced by hybridization between P.axillaris (the large white or night - scented petunia) and P.integrifolia (the violet-flowered petunia) (Skin, 1984). Petunia is used as a model plant due to its early growth habit and relatively short lifecycle, early asexual propagation from cuttings, callus or protoplasts, availability of large sets of mutants, amenity for cytogenetic analysis. Besides ornamental value, Petunia also possesses medicinal value like it has antimicrobial activity, antioxidant activity and insecticidal activity.

\section{MATERIALS AND METHODS}

\section{Washing and sterilization of explants}

For standardization of in vitro protocols, leaf explants of Petunia hybrid were collected from plants growing in Kashmir University Botanical Garden. In order to remove dirt and dust, the explants were thoroughly washed under running tap water followed by washing with detergent labolene and surfactant tween-20. The detergent was removed by washing the explants with double distilled water. Then the leaf explants were treated with chemical sterilants $2 \%$ sodium hypochlorite for 5 minutes under laminar air flow hood. This was followed by washing with autoclaved double distilled water. Finally the leaf explants were inoculated on Murashige and Skoog (1962) medium. 


\section{Medium and culture conditions}

Murashige and Skoog (1962) medium was gelled with $0.8 \%$ agar and supplemented with different concentrations of different carbon sources (sucrose, glucose, mannose, arabinose and maltose). The $\mathrm{pH}$ of the medium was adjusted to 5.8 prior to autoclaving at $121{ }^{\circ} \mathrm{C}$ and $15 \mathrm{lb}$ pressure. The cultures were finally incubated at $22 \pm 4{ }^{\circ} \mathrm{C}$ and maintained under controlled growth conditions.

\section{RESULTS}

In the present study, the effect of different carbon sources (sucrose, glucose, mannose, arabinose and maltose) on callus production and subsequent shoot regeneration from leaf explant was investigated (Table 1). MS medium supplemented with sucrose as carbon source was found to be best where on maximum number of callus was regenerated with subsequent maximum number of shoot regeneration within 11 days with 70 percent culture response (Fig.1 a). Callus and subsequent shooting was also observed on MS medium supplemented withglucose and maltose with 50 and 30 percent culture response within 18 and 24 days respectively (Fig. 1b, 1c). Keeping in view the results obtained from MS medium fortified with sucrose, the effect of different concentrations of sucrose i.e., $2 \%, 3 \%$ and $4 \%$ was seen on shoot regeneration (Table 2).MS medium supplemented with $3 \%$ sucrose was found to be best medium where on maximum number of shoots were regenerated in $70 \%$ cultures within 15 days (Fig.1d). Shoot regeneration was also obtained when 2 and 4 percent sucrose was added to MS medium with culture response of 30 and $40 \%$ within 28 and 25 days respectively (Fig. 1e, 1f). a)

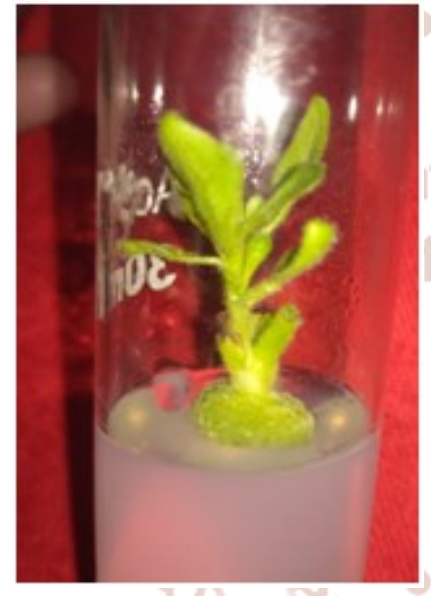

b)

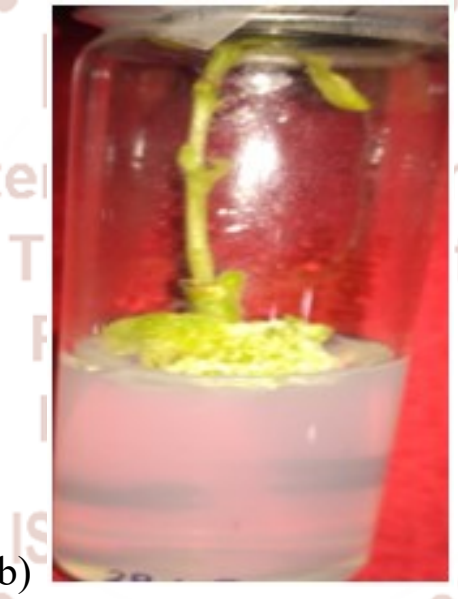

c)

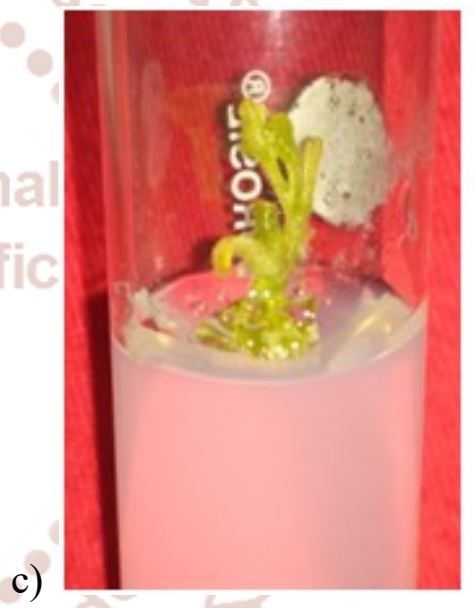

d)

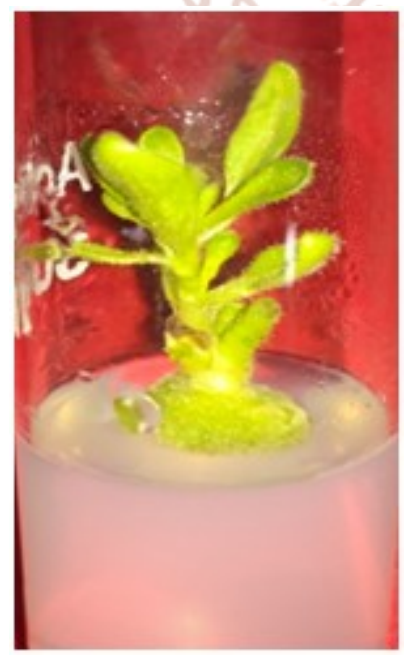

e)

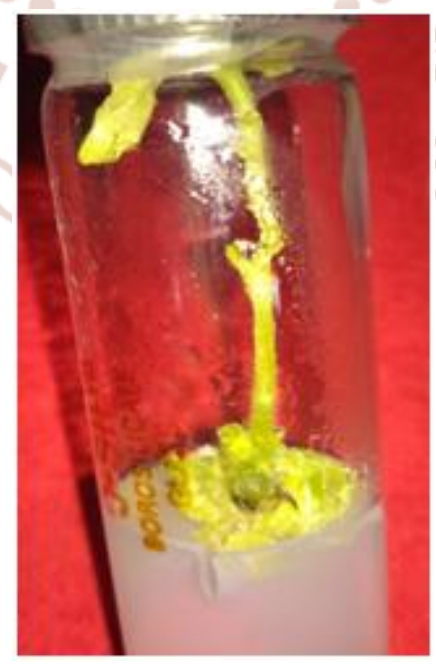

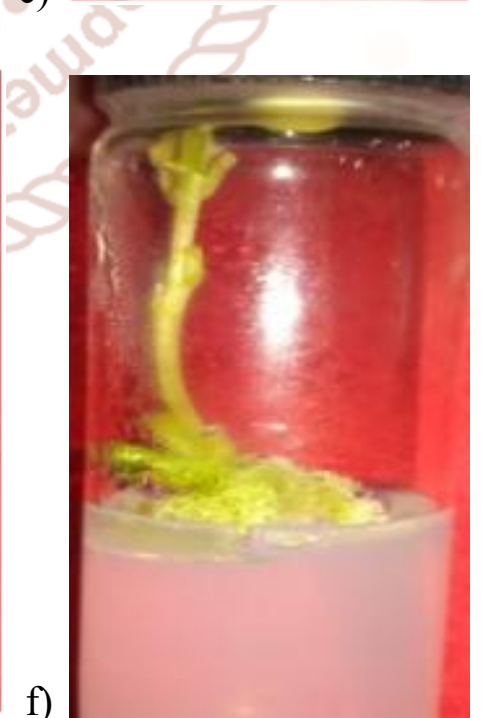

Fig.1: In vitro shoot regeneration from leaf explant on MS medium fortified with

a) Sucrose b) Glucose c) Maltose

d) $3 \%$ sucrose e) $2 \%$ sucrose f) $4 \%$ sucrose 
Table 1: Effect of MS medium fortified with different carbon sources on shoot regeneration of Petunia hybrid:

\begin{tabular}{|c|c|c|c|}
\hline $\begin{array}{l}\text { Carbon } \\
\text { source }\end{array}$ & $\begin{array}{c}\text { Callus } \\
\text { induction }\end{array}$ & $\begin{array}{l}\text { No. of days } \\
\text { taken for } \\
\text { shooting }\end{array}$ & $\begin{array}{l}\text { \% Culture } \\
\text { response }\end{array}$ \\
\hline Sucrose & + & 11 & $70 \%$ \\
\hline Glucose & + & 18 & $50 \%$ \\
\hline Maltose & + & 24 & $30 \%$ \\
\hline mannose & - & - & - \\
\hline Arabinose & - & - & \\
\hline
\end{tabular}

- No response; + Positive response

Table 2: Effect of MS medium fortified with different concentrations of sucrose on shoot regeneration of Petunia hybrid:

\begin{tabular}{|c|l|l|c|}
\hline $\begin{array}{c}\text { Carbon } \\
\text { source }\end{array}$ & $\begin{array}{c}\text { Callus } \\
\text { inductio } \\
\text { n }\end{array}$ & $\begin{array}{c}\text { No. Of days } \\
\text { taken for } \\
\text { shooting }\end{array}$ & $\begin{array}{c}\% \\
\text { Culture } \\
\text { response }\end{array}$ \\
\hline $2 \%$ Sucrose & ++ & 18 & $30 \%$ \\
\hline $3 \%$ sucrose & +++ & 11 & $70 \%$ \\
\hline $4 \%$ sucrose & + & 24 & $40 \%$ \\
\hline
\end{tabular}

+ low amount; ++ moderate amount; +++ high amount

\section{DISCUSSION}

The aim of present study was to investigate the effect of different carbon sources on the growth of Petunia hybrida. The present study reveals that sucrose at 3\% concentration showed best results in terms of callus induction and shoot regeneration. Similar results were obtained by Marcelinaet al. in 2015 . He observed the highest number of shoots in case of Petunia cv.' Prism Rose', on MS medium supplemented with sucrose. Our results are also in accordance with that of Yistraet al., who also found in vitropollen germination of Petunia hybridaon MS medium containing sucrose as a carbon source. Mahadevet al. (2014) also studied the impact of different carbohydrates and their concentrations on in vitro regeneration of Solanumviarum (Dunal). He observed that the maximum number of shoots and shoot length was obtained on MS medium supplemented with $4 \%$ fructose. Our results are in contrast with that of Raquin(1983)who observed maltose as a carbon source best for in vitro anther culture of petunia.

\section{REFERENCES}

1. Ando, T., Ishikawa, N., Watanabe, H., Kokubun, H., Yanagisawa, Y., Hashimoto, G., Marches, E and Suarez, E. A. (2005). Morphological study of Petunia integrifoliacomplex (Solnaceae). Annuals of Botany. 96: 887-900

2. Mahadev, N.D.M., Panathula, S.C., Naidu, V.C. (2014). Impact of differentcarbohydrates and their concentrations on in vitro regeneration of Solanumviarum (Dunal) - Animportant anticancer medicinal plant. American Journal of Plant Sciences. 5:200-204.

3. Krupa-Małkiewicz, M., Fornal, N., Kosatkal, A. (2018). Effect of Carbohydrate source on in vitro propagation and rooting of two cultivars of Petunia (Petunia $\times$ Atkinsiana D. Don). Agric Aliment PiscZootech. 322:67-78.

4. Raquin, C., (1893). Utilization of different sugars as carbon source for in vitro anther culture of Petunia. Zeitschrift Fur Pflanzenphysiologie. 111:453-457

5. Skin, K, C. (1984). Taxonomy.In: Sink KC, ed. Petunia.New York: Springer, 3-9.

6. Yistra, B., Garrido, D., Jacqueline Busscher, J., Tunen, J.A., (1998). Hexose Transport in Growing Petunia Pollen Tubes and Characterization of a Pollen-Specific, Putative Monosaccharide Transporter. DOI: https://doi.org/10.1104/.118297. 